\title{
CONSIDÉRATIONS SUR LE PROBLÈME BOÏEN
}

\author{
MIKLÓS SZABÓ \\ Institut Archéologique, l'Université Lorand Eötvös, \\ Faculté des Lettres, Muzeum krt. 4/B, H-1088 Budapest, Hongrie \\ szabo.miklos@btk.elte.hu
}

\begin{abstract}
The problems of Boius history have their roots in the identification of antique Boiohaemum with medieval Bohemia, an interpretation that has its origins in the tenth century. Any attempt to localize their territory, consideration must be taken of the fact that according to Tacitus, Strabon and other antique writers, this region incorporated the settlement area of King Marobodus and his Marcomanni, the so-called Bouiaimon. Other data suggest that the "land of the Boii" was a forest between the upper course of the Rhine River and present-day eastern Slovakia, along the Danube.

The Marcomanni expelled the Boii from this area at the end of the first century BC. On this basis it may be hypothesized that the settlement area of this Celtic tribe was located somewhere in present-day south-western Slovakia. The settlement of the Boii in present-day Czech Republic, however, is a historical topos. Clarifying the correct location of this tribe may contribute to a better understanding of the development and history of the Boii in Pannonia."
\end{abstract}

Le fond du problème est constitué par l'identification médiévale de l'ancien Boiohaemum (Bouiaimon) de Marobod, sous forme de Bohemia, au territoire de la Bohême actuelle, unifié par les princes de Prague au $X^{\mathrm{e}}$ siècle. ${ }^{1}$ Il s'agit d'une époque historique où des nouvelles nations d'Europe cherchaient leur identité. Ainsi, les Hongrois étaient parfois identifiés aux Scythes ou aux Huns d'Attila, les Polonais aux Sarmates.

Nous devons à K. Zeuss la réception de cette identification pour l'histoire dans son étude „Die Deutschen und die Nachbarstämme”, publiée en 1837 qui, dans ce qui suit, a été quasi généralement acceptée par les recherches protohistoriques. ${ }^{2}$ En réalité, il s'agit de la naissance d'un topos, d'un lieu commun, étant présent même aujourd'hui dans l'interprétation des connaissances géographiques de l'antiquité relatives au monde des Celtes orientaux. Alors, si le nom de la Bohême historique dérive directement de l'ancien Boiohaemum, dans ce cas-là cette région précise devait correspondre à la patrie des Boïens. Les conséquences de cette idée étaient multiples, ainsi les hypothèses concernant des mouvements migratoires des Boïens du territoire de Bohême vers l'Italie ou le bassin des Carpates.

La localisation du Boiohaemum est cependant inséparable de celle de la forêt Hercynienne (Herkynios ou Orkynios drymos, Hercynia silva), à l'intérieur de laquelle se trouva selon Strabon (VII, 1,3), Tacite (Germania 28), Velleius Paterculus (II, 109) le Bouiaimon du roi Marobod et de ses Marcomans. Tacite confirme que les Boïens ont été chassés par les Marcomans. (Germ. 42.)

De la sorte, ,la patrie des Boïens” faisait partie de cette forêt, comme l'affirmait entre autres à plusieurs reprises Velleius Paterculus (II, 108-109) mentionnant en plus Carnuntum, comme la ville du Norique la plus proche de cet endroit. Il est donc fautif de prétendre que ces deux notions géographiques correspondaient totalement l'une de l'autre. Pour cette idée fausse citons à titre d'exemple l'interprétation de J.-J. Hatt du passage de Tite-Live (V, 34) évoquant le synchronisme de l'invasion celtique vers l'Italie et la forêt Hercynienne, selon laquelle il faut mettre en

${ }^{1}$ ONDROUCH 1959, 64.
${ }^{2}$ Cf. OndROUCH 1959, 64-65, note 3.

Acta Archaeologica Academiae Scientiarum Hungaricae 66 (2015) 267-280 0001-5210/\$20.00 (C) 2015 Akadémiai Kiadó, Budapest 


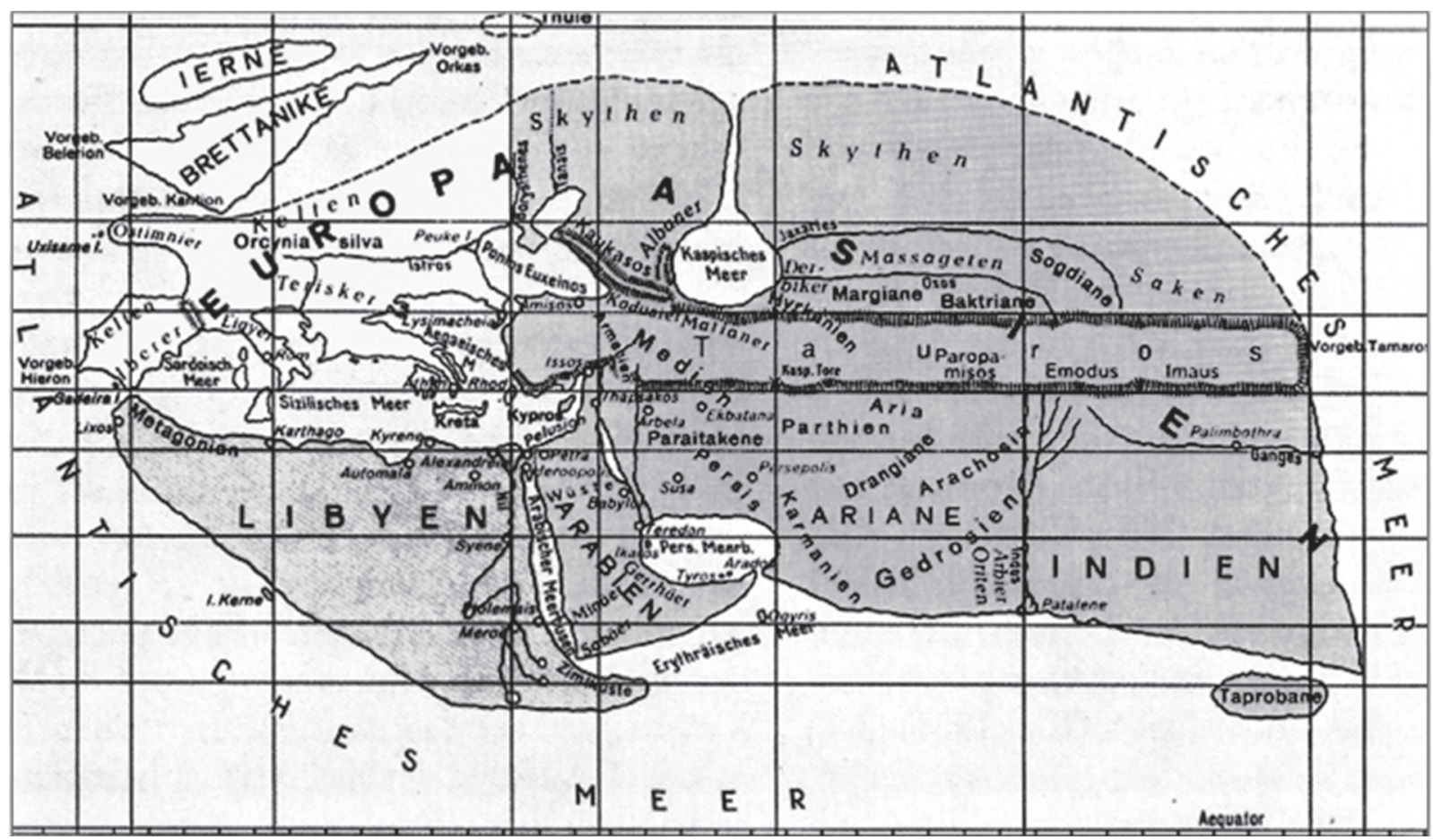

Fig. 1. Restitution de la carte d'Érathostène. (D'après DANNHEIMER-GEBHARD 1993, fig. 2)

doute l'authenticité de l'information de l'historien romain concernant la direction orientale de la migration, puisque la fameuse forêt doit être identifiéé à la Bohême, une des régions depuis longtemps occupée par des Celtes. ${ }^{3}$

Depuis Aristote (Meteorologica 1,13), on constate le caractère imprécis et ambigu de la notion antique „forêt Hercynienne”. César définit ainsi la forêt: „Elle commence aux frontières des Helvètes, des Némètes et des Rauraques, et, en suivant la ligne du Danube, va jusqu'aux pays des Daces et des Anartes; à partir de là, elle tourne à gauche, en s'écartant du fleuve."(B. G. VI, 25.) En interprétant ce texte, on se rend compte que l'Hercynia silva peut être n'importe quelle partie de la région montagneuse et forestière s'étendant au nord du Danube, entre le cours supérieur de Rhin et la Slovaquie orientale. (Fig. 1) En ce qui concerne la fin de cette citation, il a été très bien démontré que ce n'est pas la forêt qui tourne à gauche, mais le fleuve à droite, le coude du Danube étant, à cette époque-là, inconnu des géographes anciens. ${ }^{5}$

Strabon parle plusieurs fois du Hercynios drymos (IV, 6,9, VII, 1,3; 1,5; 2,2, etc.). Il dit (VII,2,2) que les Boïens habitaient autrefois la forêt Hercynienne, ce qui pourrait grosso modo correspondre à l'idée de César (B.G. I,5) selon laquelle ils étaient d'abord établis au-delà du Rhin. Évidemment, du point de vue géographique ces deux informations ne sont pas claires du tout. La description détaillée de Strabon s'inspire de l'itinéraire de Tibère (VII, 1,5). Les points de repère sont la source de l'Istros et celle du Rhin, puis le lac plus au sud que les sources de l'Istros, donc le lac de Constance, le Lacus Brigantius dans Pline (HN IX, 63). Ensuite, il énumère les Vindéliciens, puis, probablement, les Noriques et enfin le désert des Boïens avec „les peuples qui vivent là jusqu'à la Pannonie”. Un autre passage (VII, 1,3) nous informe des tribus germaniques qui vivent dans la forêt et aussi du Boiohaemum qui appartient au roi Marobodos. Mentionnant une autre forêt (allé hylé), la Gabréta hylé, Strabon fournit un repère important pour la délimitation vers le nord et le nord-ouest de la forêt Hercynienne (VII, 1,5: „Alors que la forêt Hercynienne est de l'autre côté du pays des Suèves, il y a de ce côté-ci une autre forêt..., la forêt de Gabréta." ${ }^{6}$. La Gabréta est le plus souvent identifiée aux Böhmenwald (Forêt de Bohême) et Šumava, mais son appartenance

${ }^{3}$ HatT 1977, 157-158; cf. Dobesch 1993, 10: „Poseidonios hat also gewußt, daß die Boier zur Zeit der Kimbern im herzynischen Wald wohnten, offenbar in Böhmen."
${ }^{4}$ Trad. L.-A. Constans, Paris, Les Belles Lettres, 1972.

${ }^{5}$ Mócsy 1962, 532.

${ }^{6}$ Trad. R. Baladié, Paris, Les Belles Lettres, 2008. 

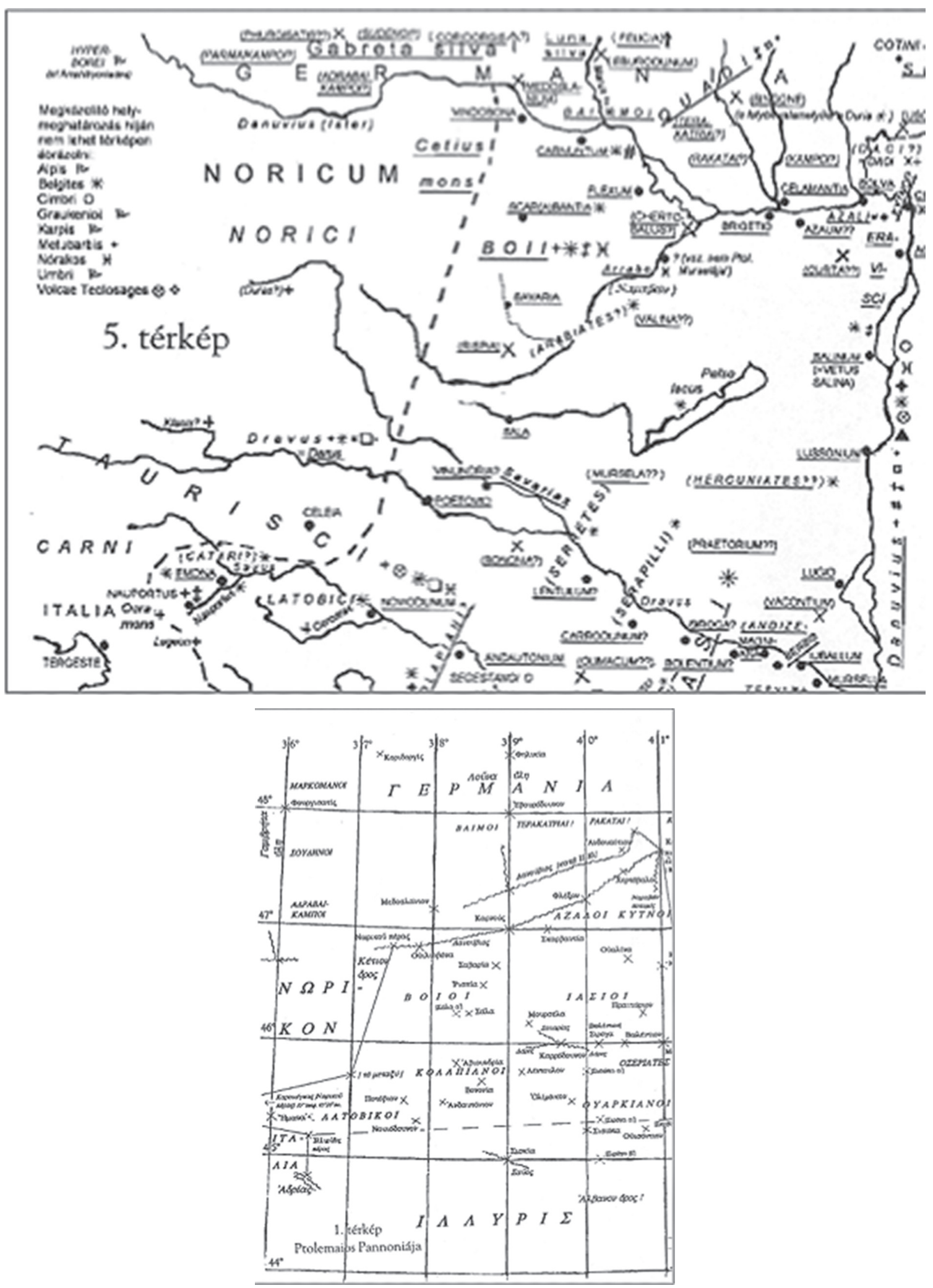

Fig. 2. Propositions pour la localisation de la Gabréta hylé (D’après FeHÉR-KovÁcs 2003). a: Les données de Ptolemaios; b: La carte historique de Pannonie, vers 54 ap. J.-C. 


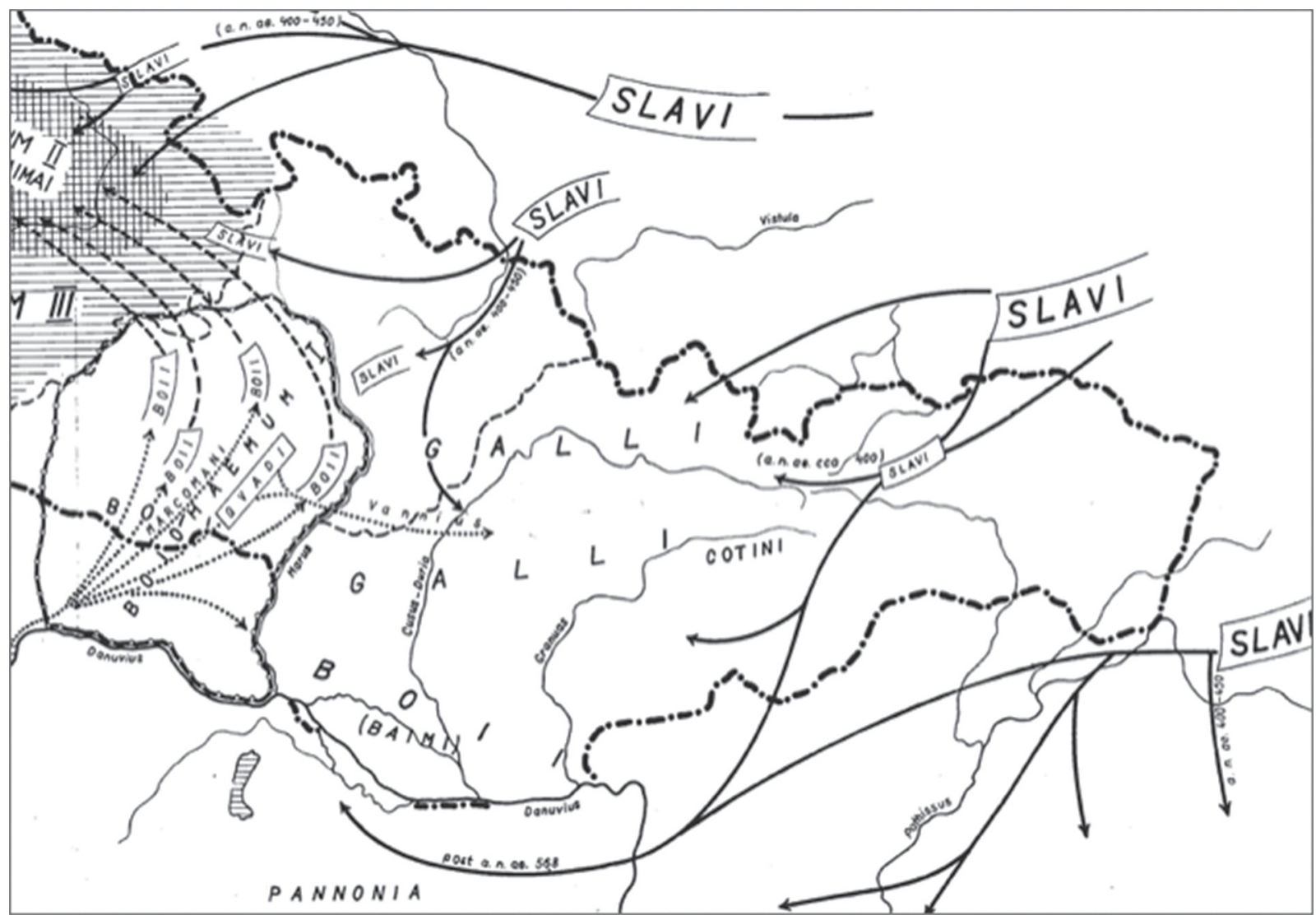

Fig. 3. Le Boiohaemum de Marobod (D'après ONDROuch 1959)

aux chaines de la forêt Hercynienne peut être à juste titre mise en doute. ${ }^{7}$ (Fig. 2.a-b) Une donnée tardive est celle de Claudius Ptolémaios (II, 11, 5) remontant au II ${ }^{\mathrm{e}}$ siècle ap. J.-C., qui élargit ou plutôt modifie pour les Sudètes le territoire de la forêt Hercynienne. ${ }^{8}$ Cette donnée reflète avant tout l'incertitude qui concerne la délimitation vers le nord de l'ensemble des massifs en question, elle peut, cependant, comme on verra plus tard, inspirer une interprétation surprenante.

Laissant de côté la critique des sources concernant le rôle d'Ératosthène (César BG VI,14) ou de Posidonios pour les connaissances géographiques des deux auteurs, ${ }^{9}$ la conclusion de cet aperçu peut être avant tout la constatation que la localisation de la forêt Hercynienne coïncidant avec la Boiohaemum repose sur les données de César et Strabon, complétées par les informations de Velleius Paterculus, en n'oubliant pas celles de Pline l'Ancien. (HN IV, 25.) D'autre part, les repères géographiques exclurent que le Boiohaemum de Marobod soit identifié avec le territoire de la Bohême actuelle. ${ }^{10}$ En conséquence, les Bö̈ens et le Boiohaemum doivent être localisés sur le territoire du bassin des Carpates, au nord du Danube, dans une région délimitée au nord par la partie orientale (morave) de la forêt Hercynienne. ${ }^{11}$ La zone peut correspondre grosso modo à la Slovaquie du Sud-Ouest, ${ }^{12}$ mais la proximité de Carnuntum, évoquée par Velleius Paterculus (II, 109), peut signifier l'extension du territoire boïen en Autriche orientale et dans la Moravie voisine. (Fig. 3) ${ }^{13}$ Par contre, la formation de la frontière orientale constituée par le Marus (Morava) (Pline l'Ancien HN IV,25) ne peut pas précéder l'expansion dace vers les années 60 av. J.-C. ${ }^{14}$

${ }^{7}$ Cf. KRUta 2000, 663; Ondrouch 1959, 81

${ }^{8} \mathrm{Cf}$. Ondrouch 1959, 81-82.

${ }^{9}$ Cf. Malitz 1983; Dobesch 1995.

${ }^{10} \mathrm{Cf}$. OndROUCH 1959, 82.
${ }^{11} \mathrm{Cf}$. Ondrouch 1959, 82-83.

${ }^{12}$ Mócsy 1962, 529; SZABÓ 2007, 11.

${ }^{13} \mathrm{Cf}$. OndRouch 1959, carte 1 : Boiohaemum I.

${ }^{14}$ Cf. Ondrouch 1959, 83; SzABó 1992, 64-67. 
L'extrémité occidentale du Boiohaemum pose problème à cause des données sporadiques, comme celle témoignant de l'existence de la ville Boioduron (près de Passau) sur le territoire des Vindéliciens ou de la présence d'un Boios à Manching. Les interprétations qui s'y rapportent sont contradictoires, à partir de l'idée de l'occupation de la région par les Boïens, jusqu'à la négation de leur poussée vers l'ouest. ${ }^{15}$ Laissant de côté cette situation mal documentée, retournons au noyau esquissé du territoire boïen. La localisation proposée peut être la clé de la situation relatée par Strabon (VII, 2,2; d'après Posidonios) en 114 av. J.-C., quand la migration des Cimbres a traversé le bassin des Carpates: Poséidonios [...] dit encore que la forêt Hercynienne était primitivement (proteron) habitée par les Boïens, que la poussée des Cimbres s'exerça d'abord sur cette région, mais refoulés par les Boïens, ils descendirent vers la Danube et les Scordisques, qui sont des Gaulois, continuèrent par les Tauristes ou Taurisques, eux aussi de race gauloise, ensuite par les Helvètes. ${ }^{16}$ (Fig. 4)

Ce passage de Strabon nous permet de constater que vers la fin du II ${ }^{e}$ siècle av. J.-C. trois peuples celtiques se partageaient le bassin des Carpates: les Bö̈ens au nord, les Scordisques au sud-est et les Taurisques au sud-ouest. ${ }^{17}$

On arrive ainsi au problème très controversé de l'origine des Boïens dits de Pannonie.

Il est indéniable qu'avant le milieu du Ir siècle av. J.-C., c'est-à-dire durant une période précédante l'attaque des Daces, le pouvoir boïen a contrôlé la partie septentrionale du bassin des Carpates jusqu'à la rivière du Parisos (Tisza). ${ }^{18}$ Il paraît logique d'expliquer cette situation par un passage de Strabon $(\mathrm{V}, 1,6)$ selon lequel après leur soumission en 191 av. J.-C., les Boïens d'Italie, chassés par les Romains, s'installèrent sur les rives de l'Istros où ils vécurent aux côtés des Taurisques. ${ }^{19}$ Notons qu'aucune autre source ne confirme directement cette donnée, mais selon Polybe (II, 35), les Galates (donc les Celtes) ,... ont été chassés de la plaine du Pô, à l'exception de quelques points situés au pied des Alpes", tandis que Pline l'Ancien (NH III, 116) constate que les Boïens avaient disparu. Bref, l'exode d'une grande partie de ce peuple est tout-à-fait probable. Grâce à la mention des Taurisques, la localisation de l'endroit indiqué par Strabon ne soulève pas de difficulté grave: il s'agit de la zone nord-ouest du bassin des Carpates. ${ }^{20}$

Dans la recherche récente le récit de Strabon était considéré comme digne de foi, même par G. Dobesch. ${ }^{21}$ Le refus par Dobesch et son école apparaît au début des années 199022: il s'agit d'un „autoschedisma” du géographe. Les arguments sont cependant fragiles, car ils reposent en grande partie sur l'identification de Boiohaemum avec l'actuelle Bohême. Selon Dobesch, la migration des Bö̈ens de l'Italie septentrionale au Danube contredit l'origine bohémienne des Boïens danubiens (Donauboier) ou pannoniens. ${ }^{23} \mathrm{C}$ 'est une hypothèse dont la fiabilité paraît de plus en plus douteuse à cause de l'interprétation géographique de la notion de la forêt Hercynienne qu'on a analysée ci-dessus.

Le grand maître de l'archéologie laténienne, J. Filip, a essayé d'élaborer des arguments archéologiques concernant l'arrivée des Boïens du Nord, de la Bohême, dans la région du Moyen-Danube à cause de la poussée germanique. ${ }^{24}$ Les recherches ultérieures ont bien démontré que cette théorie ne tient pas debout. ${ }^{25}$

À la lumière des nouvelles recherches, les éléments d'origine italienne de la civilisation de La Tène dans la région du Moyen-Danube passent au premier plan. Ajoutons d'emblée que la nature des phénomènes est souvent difficile à interpréter: sont-ils des symptômes de contacts quasi réguliers avec l'Italie ou des corollaires d'un évènement exceptionnel, plus précisément de l'installation des Boïens chassés en 191 de Cispadane dans la région du nord-ouest du bassin des Carpates. Laissant du côté des trouvailles remontant au $\mathrm{IV}^{\mathrm{e}}$ siècle, comme la situle en bronze de type dit à kalathos étrusco-italique de Mannersdorf (Basse-Autriche) ${ }^{26}$ ou les preuves du rôle joué par la Cisalpine gauloise dans la diffusion du „Style végétal continu” dans la partie occidentale du bassin des Carpates, ${ }^{27}$ énumérons les documents les plus parlant, avec la note additionnelle qu'il y a évidemment des cas moins perceptibles dans le matériel archéologique dont nous ne faisons pas mention ici.

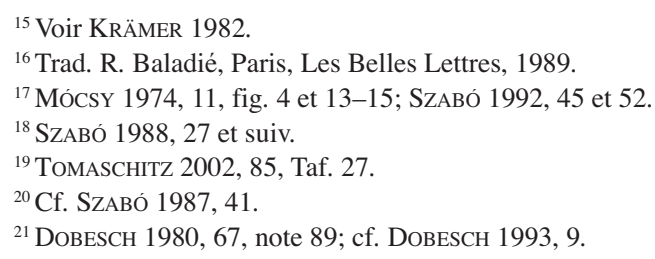

${ }^{15}$ Voir KRÄMER 1982.

${ }^{17}$ Mócsy 1974, 11, fig. 4 et 13-15; SZABÓ 1992, 45 et 52.

${ }^{18}$ SzABó 1988,27 et suiv.

${ }^{20}$ Cf. SZABÓ 1987, 41.

${ }^{21}$ Dobesch 1980, 67, note 89; cf. Dobesch 1993, 9

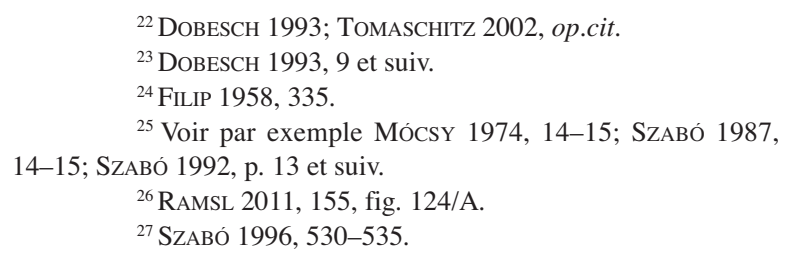




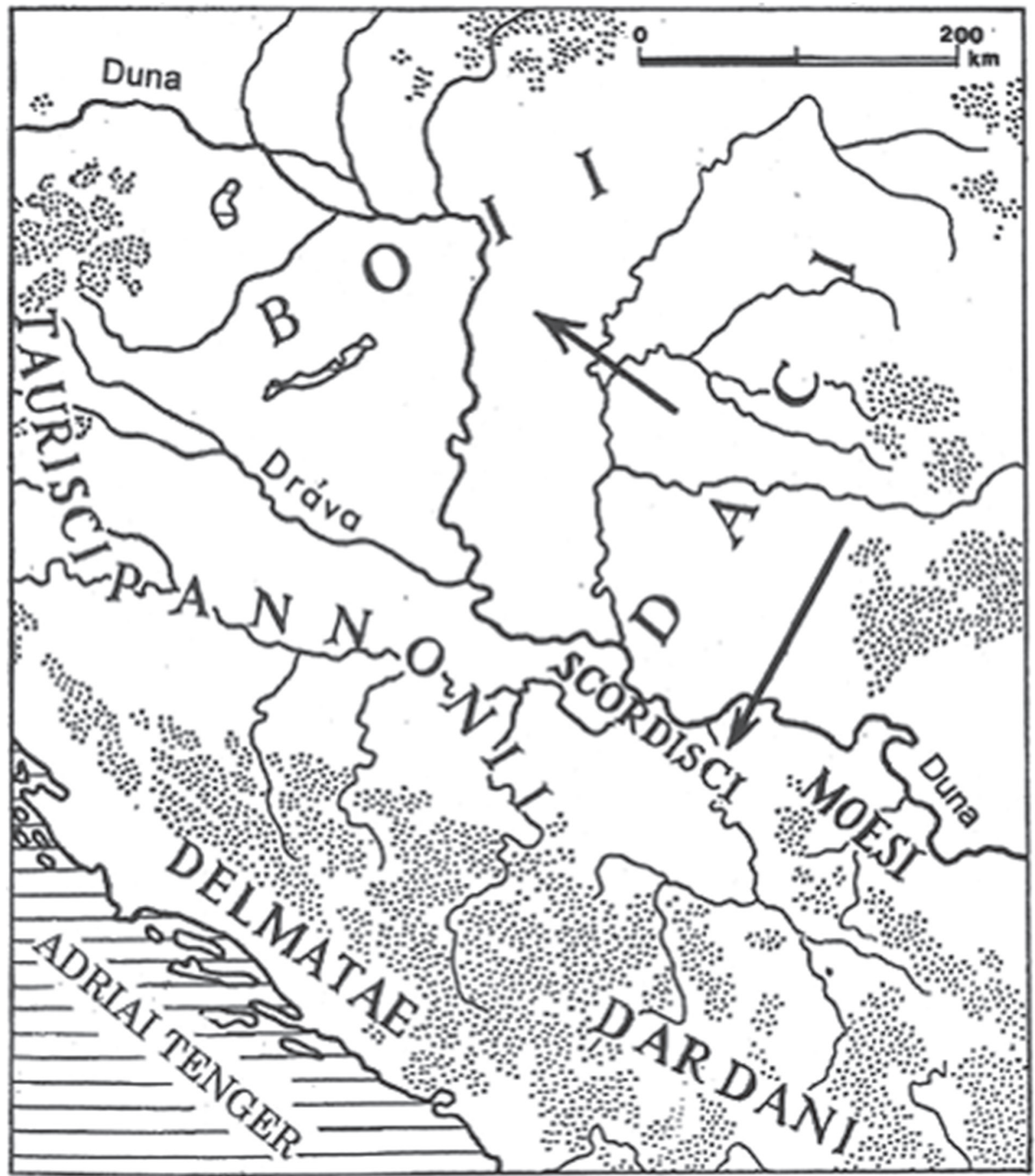

Fig. 4. Le bassin des Carpates à l'aube des offensives des Daces 

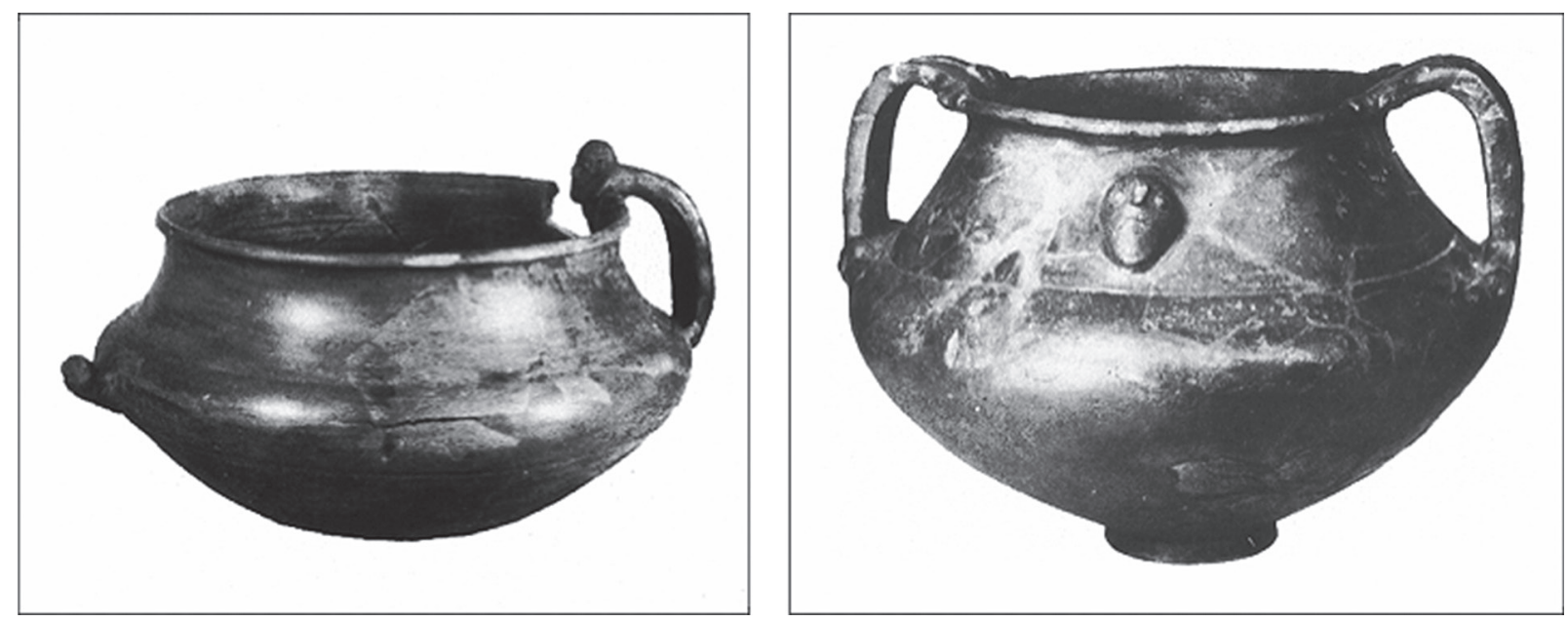

Fig. 5. a: Le vase de Balatonederics;b: Le vase de Novo mesto (D’après SzABó 1987)

Le premier indice est sans doute constitué par un aes grave romain de 235-220 av. J.-C., trouvé dans le contexte d'un habitat celtique de Nitra en Slovaquie. ${ }^{28}$

Le deuxième problème qu'il faut brièvement examiner est la possible filiation italique du décor plastique d'un groupe de la céramique danubienne de La Tène B2/C1. La forme de base à deux anses est incontestablement en rapport avec le substrat non celtique de la région: ,illyro-pannonien” à l'Ouest, ,thraco-scythe” à l'Est du Danube. ${ }^{29}$

Dans le cas des anses surmontées d'une tête humaine (par exemple sur le pseudo-canthare de Balatonederics) ou des masques qui se trouvent sur le corps de vase (Novo mesto) (Fig. 5.a-b), il est pour le moment difficile à préciser dans quelle mesure il s'agit d'un phénomène aux racines plus anciennes, comme pourrait parler en faveur d'une telle interprétation un vase de la nécropole bolonaise de La Certosa (tombe $\mathrm{n}^{\circ}$ 304) (Fig. 6.a), orné de 4 têtes humaines très proches des représentations celtiques présentées ci-dessus. Mentionnons à ce propos des réalisations analogues aux précédentes qui nous sont connues sur les cruches celtiques de LT II (Kosd, Körösszegapáti $=$ Fig. 6. ) dont la forme de base remonte aux antécédents dits thraco-scythes. ${ }^{30}$

Un autre type de vase où la figure humaine est appliquée à la panse, s'évasant en position de pont jusqu'au bord est bien répandu dans le bassin des Carpates. Aux pièces trouvées depuis longtemps en Hongrie: Kakasd (Fig. 7. a), Kosd, Rozvágy, il faut ajouter une belle série découverte récemment à Blandiana, Levice, Nyékládháza, Csepel. ${ }^{31}$

Ces vases évoquent des modèles méditerranéens grecs et étrusques qui, dans le milieu étrusque et prénestin - en ne parlant pas des patères en terre cuite d'Apulie - restent à la mode même au III ${ }^{\mathrm{e}}$ siècles av. J.-C. sur les cistes et les oenochoés. (Fig. 7.b)

De plus, des objets identiques font leur apparition dans des contextes celto-italiques aussi. Donc dans ce cas-là le rôle intermédiaire des Boïens de Cispadane vers le bassin de Carpates est assez plausible. ${ }^{32}$

Les représentants de ce groupe de céramique n'ont pas d'homologues dans la Celtique de l'Ouest. Ils appartiennent à un ensemble très particulier qui atteste la formation d'une communauté culturelle et artistique dans le bassin des Carpates. Les vases à décor plastique présentent un aspect original de la civilisation celtique orientale dont l'arrière-plan fut constitué par la fusion des éléments laténiens locaux avec l'influence d'origine italo-celtique. ${ }^{33}$ Évidemment, ces rapports entre les Celtes cisalapins et les Celtes danubiens, existant depuis le IV ${ }^{\mathrm{e}}$ siècle av. J.-C., ne peuvent pas être interprétés comme la documentation archéologique d'une éventuelle migration des Boïens d'Italie

${ }^{28}$ KolniKovÁ 1964.

${ }^{29}$ KrutA-SZABÓ 1982.

${ }^{30}$ SzABÓ 1987, 42, fig. 8-14; voir encore le pseudo-canthare de Zalakomár qui est une version totalement laténisée du type de Balatonederics: HoRvÁTH 2008, 113-116, fig. 2-7.

${ }^{31}$ Kakasd (Fig. 7.a), Kosd, Rozvágy: SzABó 1987, 42, fig. 15-17; il faut y ajouter une belle série découverte récemment: Rus-
toiu-Egri 2010, p. 223 et suiv, 269, p. 17: Blandiana; 272, pl. 20/4: Levice; 272, pl. 20/6: Nyékládháza; Zsidi 2005, 47, 48: Csepel. Voir encore HoRVÁtH 2008, 129, fig. 11.

${ }^{32}$ SzABÓ 1987, 42; cf. Rustolu-Egri 2010, 225-226, 274 , pl. 22, 1-4.

${ }^{33}$ Sur la communauté culturelle des Celtes orientaux, voir SzABÓ 1992, p. 153 et suiv. 

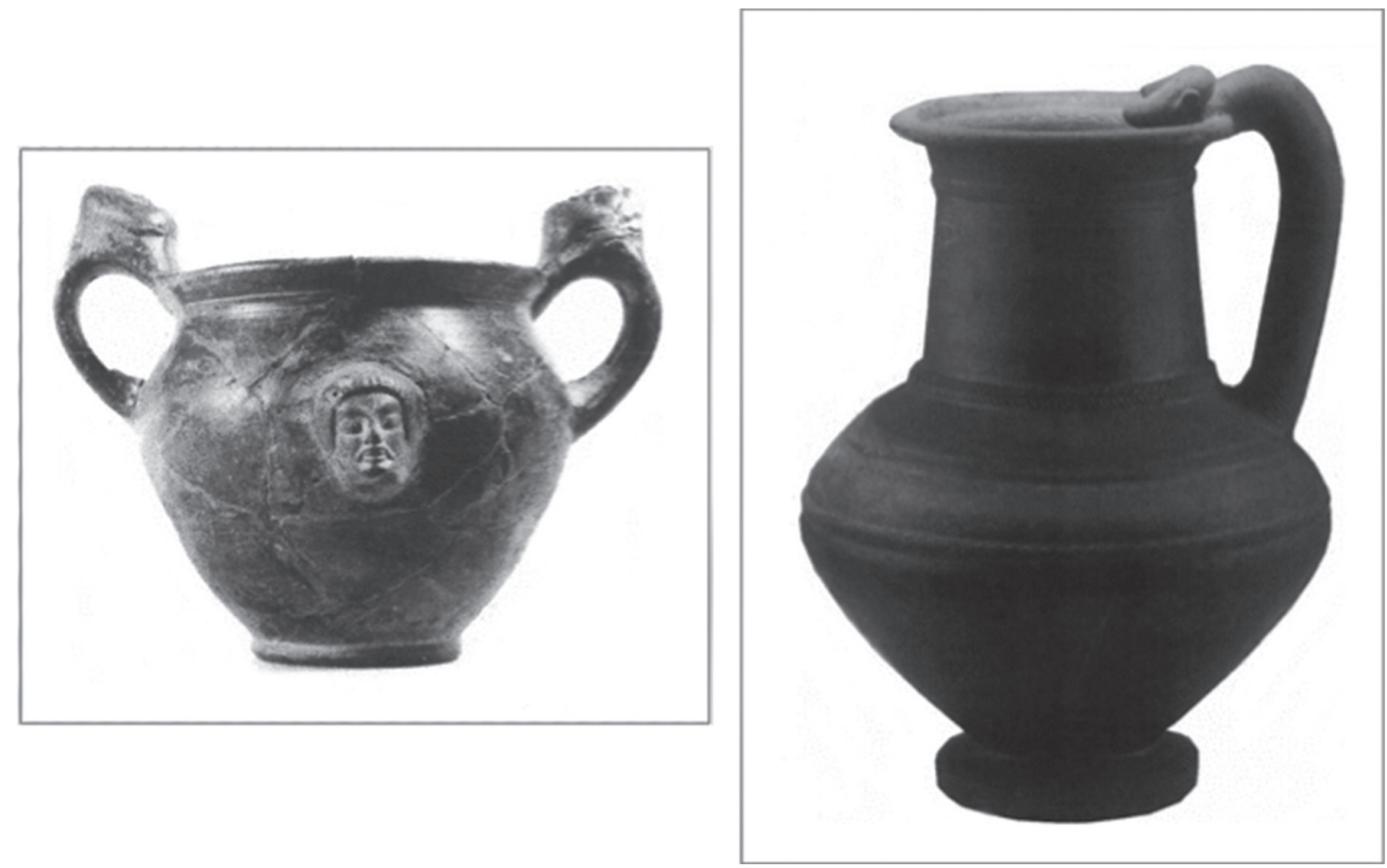

Fig. 6. a: Le vase de La Certosa tombe n³04; b: La cruche de Körösszegapáti (D’après SzABó 1987)
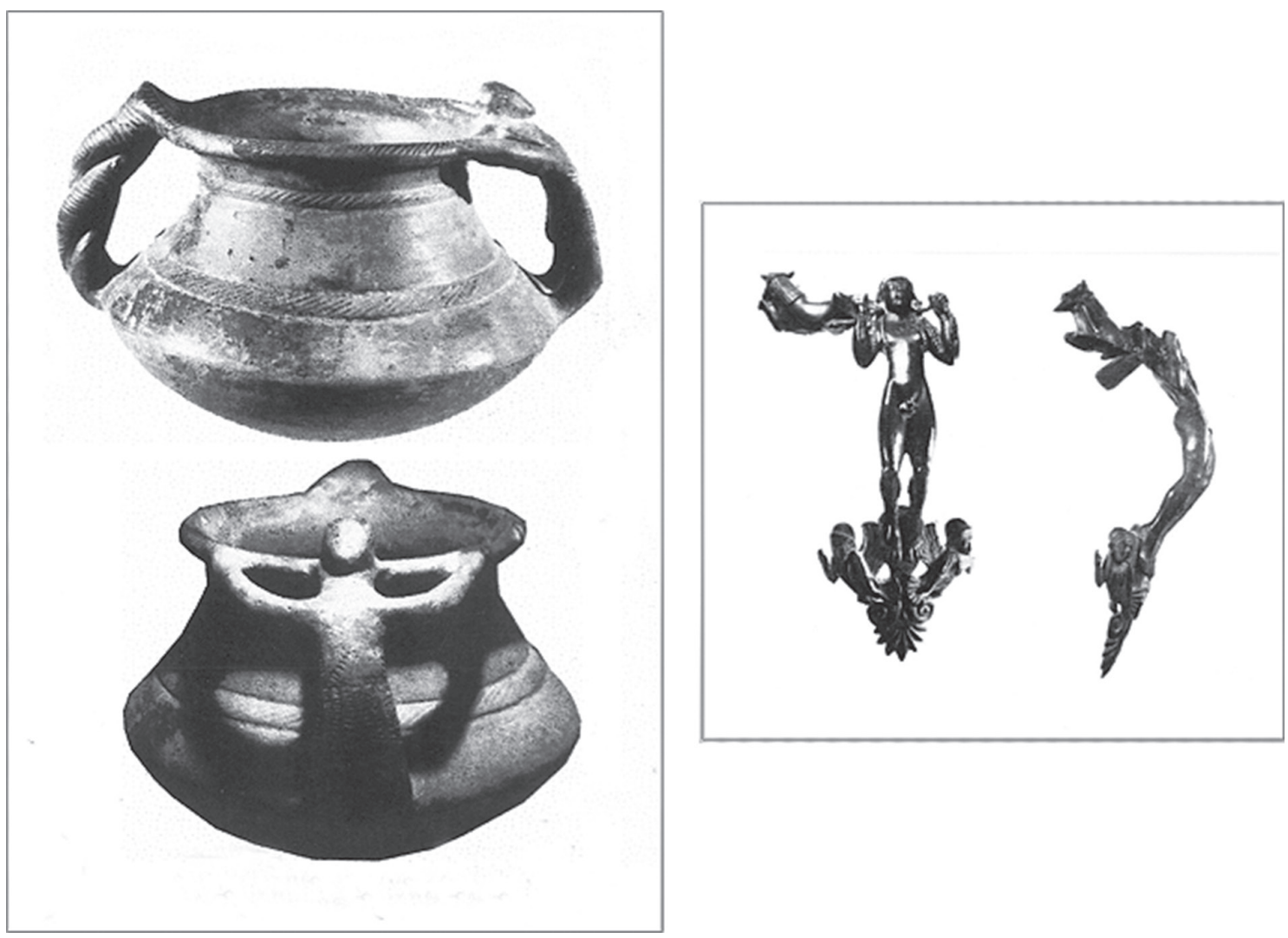

Fig. 7. a: Le vase de Kakasd (D’après SZABÓ 1987); b: Prototype archäque du motif (Malaga; d'après RusToIU 2010) 


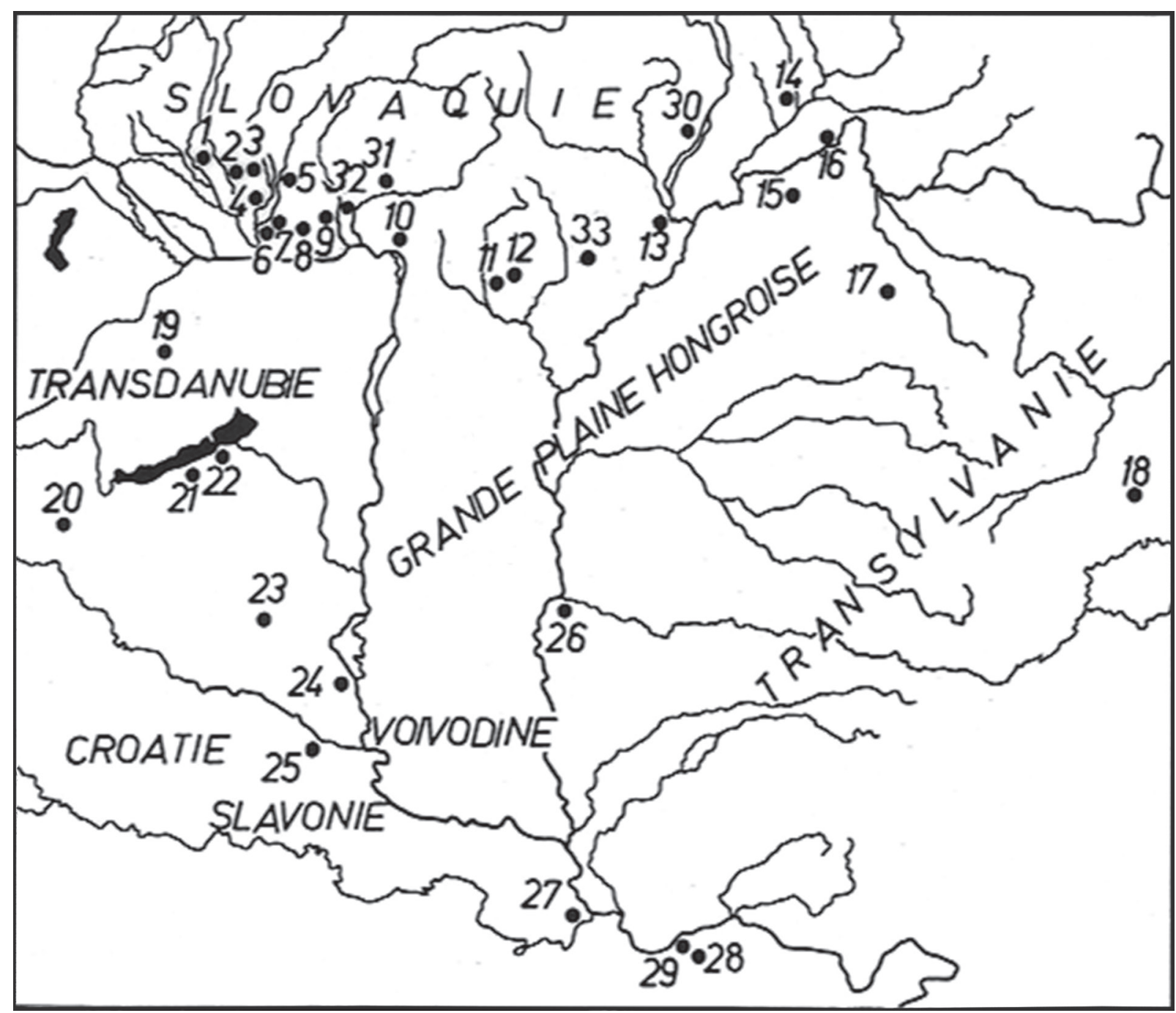

Fig. 8. La diffusion des mobiliers guerriers à la période de l'expansion balkanique (LT B2)

dans le bassin des Carpates. Par contre, ils peuvent témoigner pour les liens, peut être traditionnels, entre deux peuples celtiques bien éloignés l'un de l'autre. L'explication possible peut être l'hypothèse boïenne, c'est-à-dire la présence „anonyme” des Bö̈ens dans la région du Moyen-Danube depuis le IV ${ }^{\mathrm{e}}$ siècle. Malheuresement, on ignore le nom des premières tribus celtiques établies dans le bassin des Carpates. Cette situation commence à changer durant la période des offensives celtes contre le monde hellénistique, c'est-à-dire au début du III ${ }^{\mathrm{e}}$ siècle av. J.-C. L'hypothèse selon laquelle les Bö̈ens ont fait leur apparation sur ce territoire dès l'invasion balkanique ou même avant, n'est pas nouvelle, mais les preuves la concernant sont faibles. La variante „Tolistoboïens” du nom du peuple galate des Tolistobogiens peut en principe témoigner d'un contingent boïen qui participa également à la grande expédition de 280 av. J.-C. Si on accepte la localisation de la ,patrie des Boïens” en Slovaquie du Sud-Ouest et les régions occidentales voisines, la fiabilité de cette proposition paraît confirmée. D'autre part, les découvertes archéologiques éclairantes permettent de compter avec la participation massive des Celtes danubiens dans l'expansion balkanique.(Fig. 8) ${ }^{34}$

Dans le temps des oppida le centre tribal de Bö̈ens de Pannonie se trouvait très probablement sur le territoire de la ville de Bratislava en Slovaquie. Les nombreuses et riches trouvailles de ce site révèlent des rapports

${ }^{34}$ Voir Hubert 1989, p. 56 et suiv.; SzABÓ 1992, p. 25 et suiv.; SZABÓ 1995; KRUTA 2000, 478. 


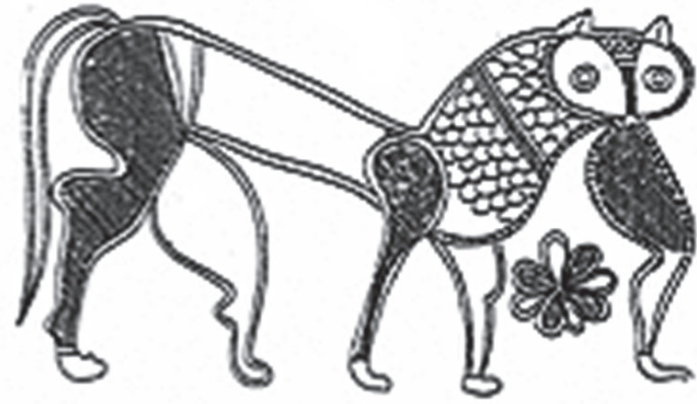

1

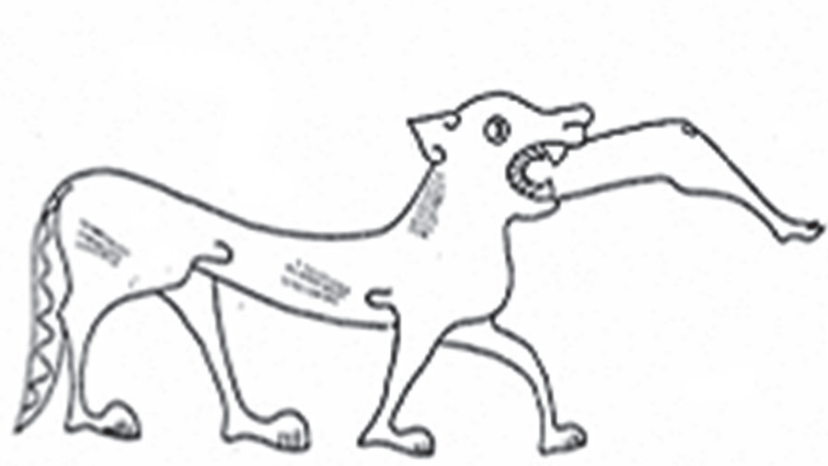

3

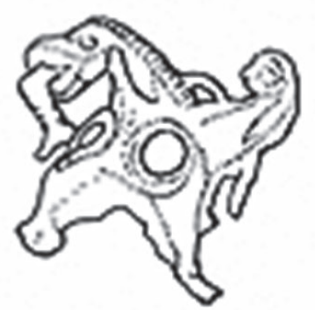

5

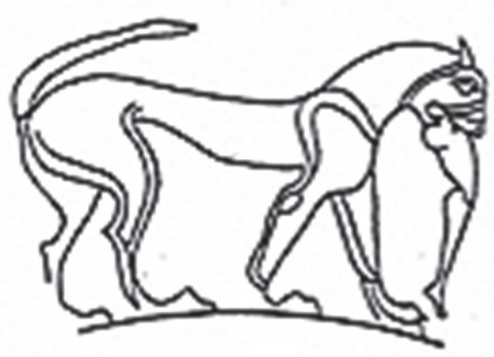

2

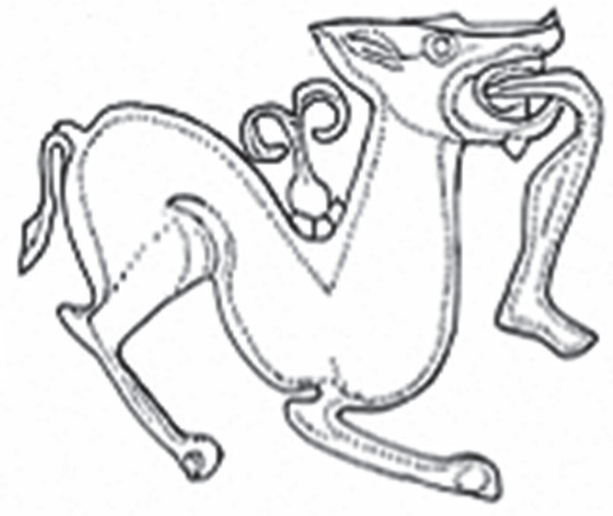

4

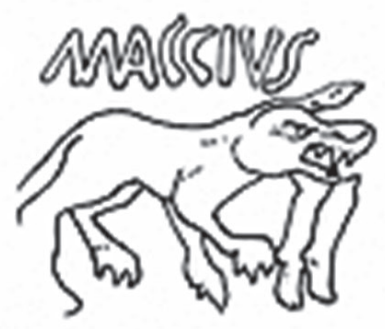

6

Fig. 9. Le motif du carnivore tenant dans sa gueule une ou deux jambes humaines. 1: Vase étrusco-corinthien à Villa Giulia (Rome); 2: Vase en bucchero de Veii; 3: Situle de Vače; 4: Matrice en terre cuite d'Este; 5: Applique en bronze de Magdalenska gora; 6: Monnaie boïenne en argent (Maccius) de Bratislava/Pozsony (D'après SzABó 2013) 


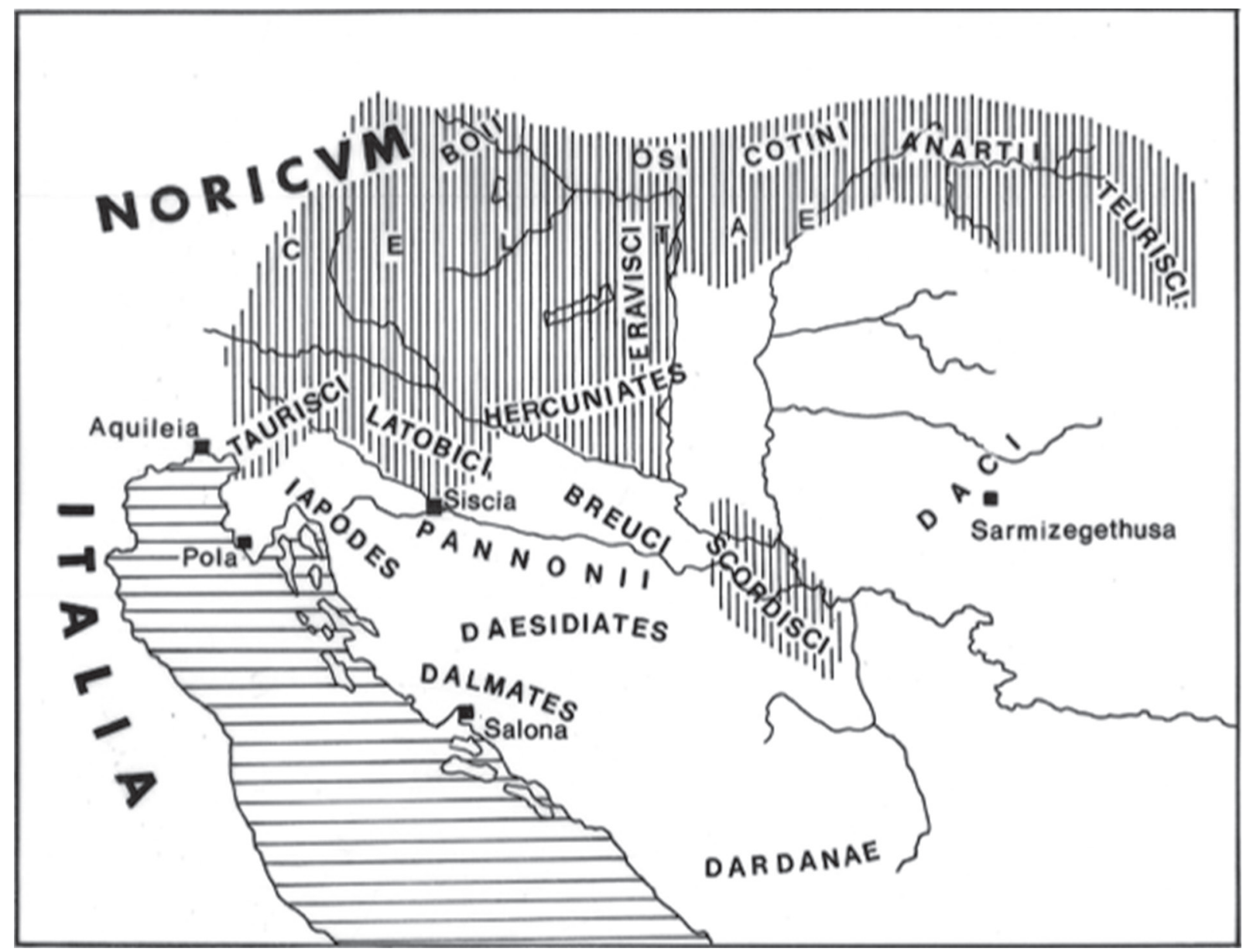

Fig. 10. Les peuples du bassin des Carpates vers la deuxième moitié du $1^{\text {er }}$ siècle av. J.-C.

avec l'Italie. La découverte la plus surprenante est une porte de l'oppidum édifiée en maçonnerie. Ce type de construction suppose des expériences acquises dans la Cisalpine gauloise. Les monnaies boïennes de type Biatec, frappées probablement à Bratislava, sont très fortement influencées par l'usage monétaire romain. Notons que, pour les légendes, elles adoptent des caractères latins. L'analyse des images monétaires mérite d'être évoquée dans le contexte qui nous intéresse: sur le revers portant l'inscription MACCIUS, se trouve un carnivore, peut-être une panthère, tenant deux jambes humaines dans sa gueule. Il s'agit d'un motif fort bien connu dans le répertoire iconographique d'origine étrusco-italique. (Fig.9) Toutes ces données parlent en faveur de l'importance de la Cisalpine dans le processus de la formation des oppida en milieu pannonien et peuvent corroborer l'hypothèse que le peuple des Bö̈ens de Pannonie était en partie constitué par leur homonyme, les Boïens de Cisalpine. ${ }^{35}$

Le déroulement des conquêtes de l'État dace, très probablemant avant la fin des années 60 av. J.-C., relaté par Strabon (VII, 3, 11; VII, 5, 2), nous fournit des données sur le territoire des Boïens de Pannonie. D'après le géographe grec, les Daces avaient des ambitions territoriales et convoitaient le Parisos (la Tisza), à la limite de la sphère de pouvoir boïenne. Ce partage territorial correspond à une situation géopolitique, évidemment postérieure à l'immigration des Boïens alors que l'enjeu des conflits devait être la région de la Hongrie actuelle qui se trouve à l'est de la Tisza. Notons que des sources plus tradives indiquent que les pourtours du nord de la Transylvanie étaient occupés par les Teurisci, ce qui confirme l'attribution de la partie du nord-est de ce territoire au domaine de 1993, p. 149 et suiv. 


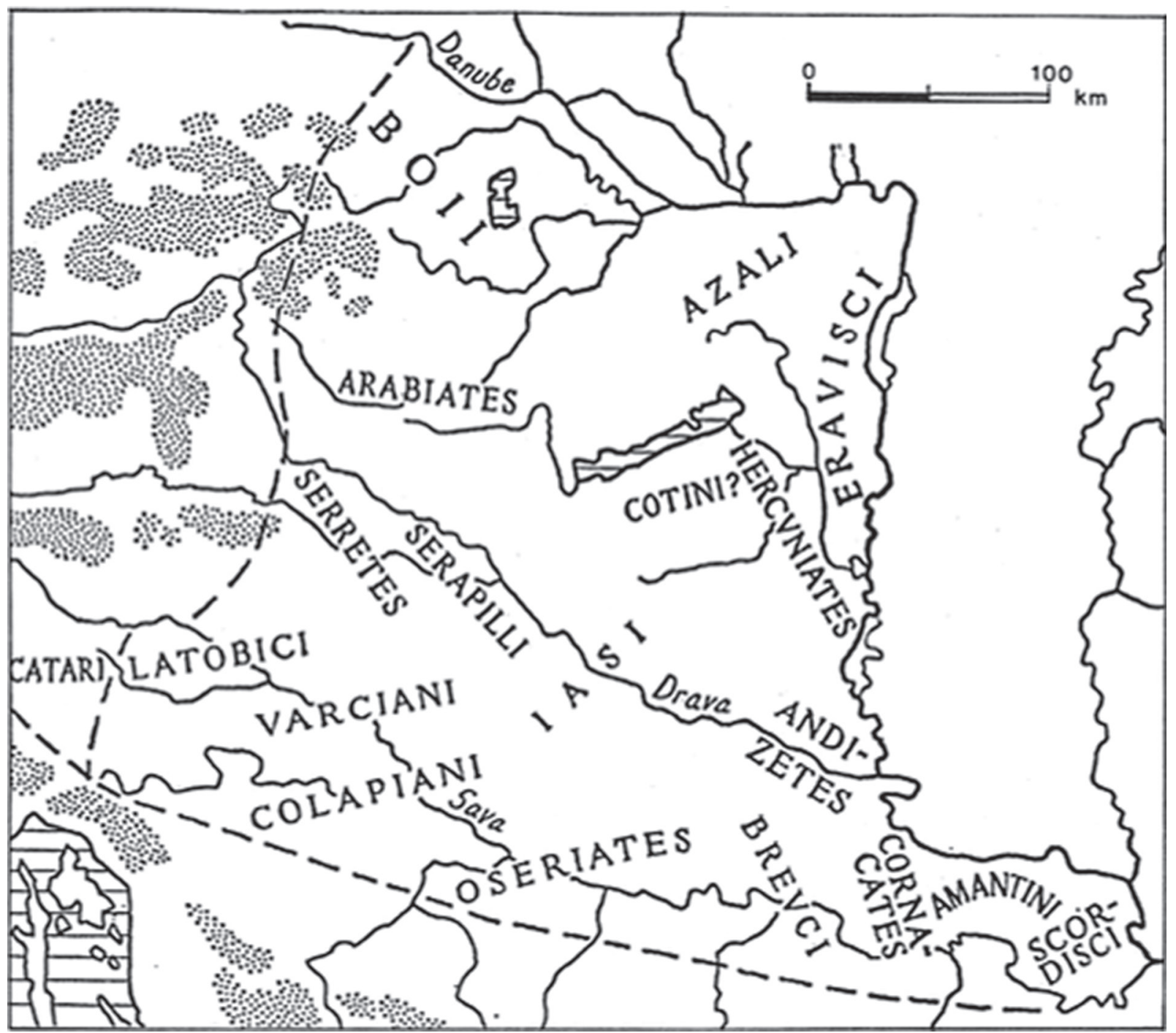

Fig. 11. Les peuples indigènes en Pannonie romaine (D’après SzABó 2007)

l'alliance des Boïens et des Taurisques. (Fig. 10) Cette dernière, dirigée par Kritasiros,a été battue par Burébiste. La localisation du champ de bataille est pour le moment impossible; la situation géo-politique est en faveur du nord-est de la Hongrie ou de la Slovaquie orientale. La dévastation de l'oppidum de Bratislava vers le milieu du Ir siècle av. J.-C. pouvait être une des conséquences de la victoire dace. ${ }^{36}$

Les sources anciennes mentionnent le deserta Boiorum (Boión erémia) (Strabon VII, 1, 5 et 5, 2; Pline l'Ancien HN III, 24, 196) lequel a été considéré comme une conséquence de la débâcle de la tribu: „la partie devenue déserte" du territoire boïen. Il est cependant vraisemblable qu'il s'agit plutôt d'un nom géographique évoquant le caractère plat et marécageux de la Transdanubie du Nord-Ouest. ${ }^{37}$ Selon une hypothèse récente, cette notion reflète la survivance d'un vieux topos, remontant à Hérodote, selon lequel les territoires au nord du Danube étaient inhabitables à cause du froid terrible qui y régnait. ${ }^{38}$ La notion deserta ou erémia signifie une région non cultivée, limitrophe du monde civilisé de l'oecumène (oikumené). Comme le deserta Getarum ou le deserta Sarmatiae. Pline l'Ancien (HN III,146) donne une localisation grosso modo précise: le „désert” est voisin du Norique et occupé par la

\footnotetext{
${ }^{36}$ Mócsy 1974, 18-21; SzABó 1992, 64-67; pour Bratislava: ZACHAR-REXA 1988.
}

${ }^{37}$ Tóth 1980, 80 et suiv.
${ }^{38}$ FeHÉR-Kovács 2005, 45-46. 


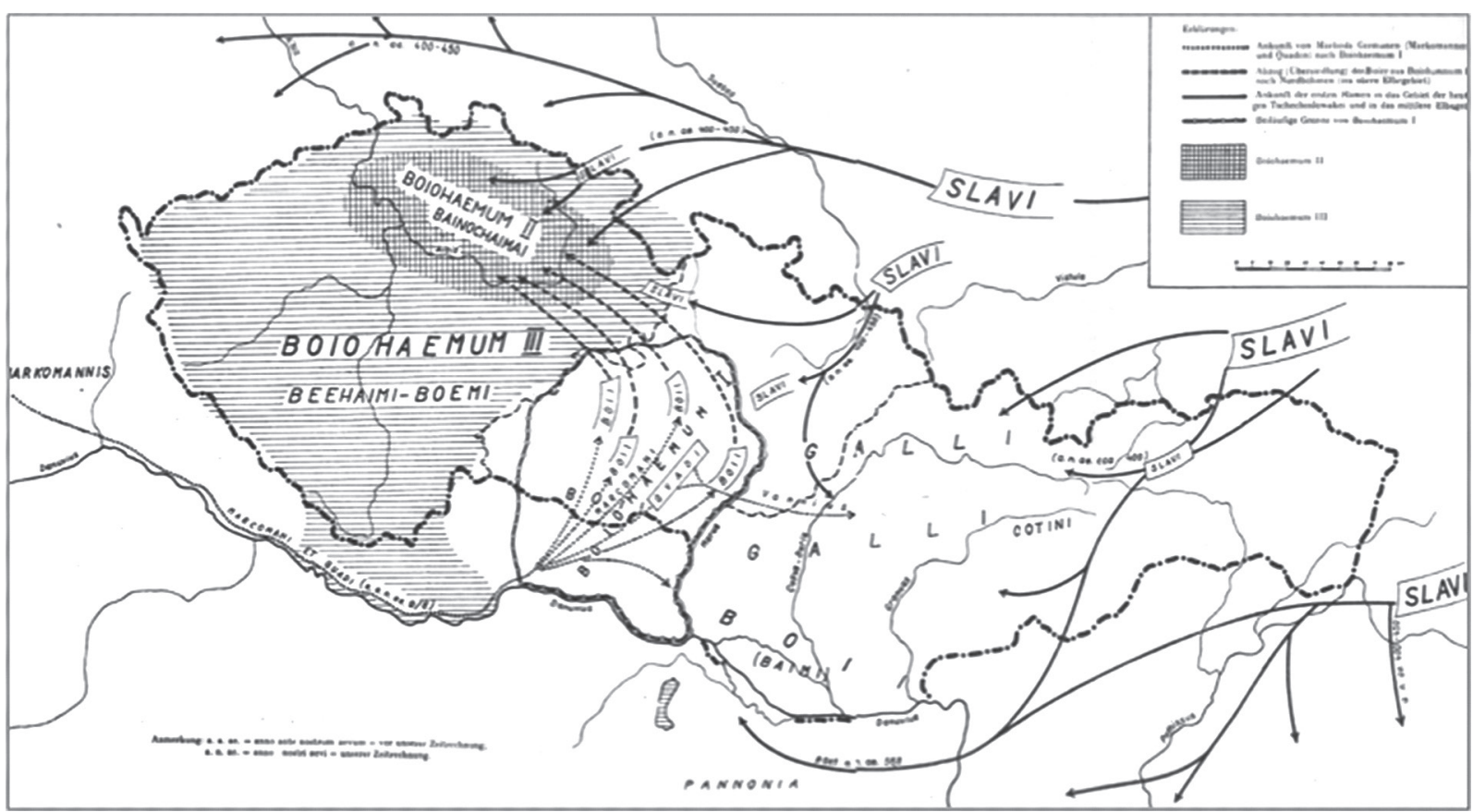

Fig. 12. La synthèse proposée par Ondrouch: Boiohaemum I, II et III (D’après ONDROUCH 1959)

colonie de Savaria et la ville de Scarbantia. Notons que la région en question était habitée à l'époque de La Tène par une population celt ${ }^{39}$ et c'est le même territoire où, à l'époque romaine, se trouvait la civitas Boiorum.$^{40}$ (Fig. 11.)

Enfin, le contingent boïen qui assiégeait en 60 ou 59 av. J.-C. la ville de Noreia ne peut pas être originaire de la Bohême ${ }^{41}$ conformément aux arguments développés ci-dessus sur la localisation de la forêt Hercynienne. L'évènement en question était très probablement la conséquence de la défaite des Bö̈ens pannoniens vers cette date, subie par les Daces de Burébiste. Finalement, l'aventure se termine en Gaule, sur le territoire des Éduens où, dans la région de Sancerre, se serait trouvé leur principal oppidum, Gorgobina (ou Gortona). ${ }^{42}$

En guise de conclusion, il faut donc à nouveau souligner que le nom Boiohaemum utilisé par les géographes anciens désigne la partie de la forêt Hercynienne habitée par les Bö̈ens et occupée à la fin du Ir siècle av. J.-C. par les Marcomans. ${ }^{43}$ Le caractère imprécis, schématique et ambigu de la notion Hercynia silva est évident. Cette constatation repose sur les études consacrées aux connaissances géographiques de Posidonios, puis celles de César et de Strabon. ${ }^{44}$ Malgré l'incertitude où nous sommes, les données dont nous disposons ne permettent pas d'insérer le territoire de la Bohême actuelle dans la forêt Hercynienne. Plus tard la localisation change, pour Ptolémée elle peut correspondre à la région reliant les Sudètes aux Carpates.

Pour finir, je voudrais juste faire référence à la synthèse proposée par Ondrouch selon laquelle le Boiohaemum I était la région occupée par Marobod, délimitée par le Danube et le Marus, comprenant aussi une partie de la Moravie et la Basse-Autriche. Le Boiohaemum II, localisé par Ptolemaios, se trouvait en Bohême septentrionale et il était probablement la création des Bö̈ens chassés par les Marcomans, tandis que le Boiohaemum III, en Bohême, est le descendant médiéval de cette notion géographique et, en même temps, éponyme de la Bohême actuelle. ${ }^{45}$ (Fig. 12)

Le territoire primitif des Boïens a dû correspondre au royaume de Marobod et à la région à l'est de Marus, donc le sud-ouest de la Slovaquie actuelle. Le rejet de l'existence des Boïens de Bohême à l'époque de La Tène, donc d'un topos historique, nous aide à mieux comprendre la formation et l'histoire des Boïens danubiens ou pannoniens.

${ }^{39}$ SZABÓ 2007 6-7, fig. 1; Petres 1990.

${ }^{40}$ Mócsy 1959, p. 49 et suiv; KovÁcs 2014, 65-75.

${ }^{41} \mathrm{Cf}$. en faveur de cette hypothèse: DobEsch 1993, 12-13.

${ }^{42}$ Cf. César, B. G. I, 5; Szabó 1992, 62; Kruta 2000, 478.
${ }^{43}$ Cf. Kruta 2000, 478.

${ }^{44}$ Cf. Dobesch 1995, 103-106.

${ }^{45}$ ONDROUCH 1959,103 , carte $n^{\circ} 1$. 


\section{BIBLIOGRAPHIE}

DANNHEIMER-GEBHARD 1993

DOBESCH 1980

DOBESCH 1993

DoBESCH 1995

FEHÉR-KovÁCs 2005

FILIP 1958

НАTт 1977

HORVÁTH 2008

Hubert 1989

KolNIKOVÁ 1964

KovÁCs 2014

KRÄMER 1982

KRUTA-SZABÓ 1982

MaLiTZ 1983

Mócsy 1959

MócSY 1962

MóCSY 1974

ONDROUCH 1959

Petres 1990

Pieta-ZACHAR 1993

RAMSL 2011

RUSTOIU-EGRI 2010

SZABÓ 1987

SZABÓ 1988

SZABÓ 1992

SZABÓ 1995

SZABÓ 1996

SZABÓ 2007

SZABÓ 2013

ToMAschITZ 2002

То́тн 1980

ZACHAR-REXA 1988

ZSIDI 2005
= H. DANNHEIMER-R. GebhaRd (éds): Das keltische Jahrtausend. Mainz 1993.

= G. Dobesch: Die Kelten in Österreich nach den ältesten Berichten der Antike. Wien-Köln-Graz 1980.

= G. Dobesch: Anmerkungen zur Wanderung der mitteleuropäischen Boier. Tyche 8 (1993) 9-17.

= G. DoBEsch: Das europäische „Barbaricum” und die Zone der Mediterrankultur. Tyche Supplementband 2. Wien 1995

= B. FeHÉR-P. KovÁcs: Early Geographers - the Period of the Roman Conquest. Fontes Pannoniae Antiquae 1. Budapest 2005.

= J. FILIP: Böhmen und der Karpatenkessel am Ende des letzten Jahrtausends. ActaArchHung 9 (1958) 353-356.

= J.-J. HatT: De Denys d'Halicarnasse à Tite-Live. Chronologie des invasions celtiques en Italie du Nord. In: Hommage à la mémoire de Jérôme Carcopino. Paris 1977, 157-159.

= L. HoRvÁth: Kelta pseudo-kantharos Zalakomárból (Zala m.) (Celtic pseudo-cantharus from Zalakomár - Hungary, Zala county). ZalaiMúz 17 (2008) 109-129.

$=$ H. Hubert: Les Celtes depuis l'époque de La Tène et la civilisation celtique. Paris 1989.

= E. KolniKovÁ: Nález rimského aes grave s keltskymi mincami v Nitre (Fund eines römischen Aes grave gemeinsam mit keltischen Münzen in Nitra). S1A 12/2 (1964) 391-408.

= P. KovÁcs: Natione Boius, avagy mi történt a boiusokkal? (Natione Boius, ou bien qu'est-ce qui s'est passé avec les Boïens?). In: P. Kovács-B. Fehér (éd.): Studia epigraphica Pannonica. 6: Felírattani újdonságaink 2014-ben. TITE könyvek 6. Budapest 2014.

= W. KRÄMER: Graffiti auf Spätlatènekeramik aus Manching. Germania 60 (1982) 489-499.

= V. Kruta-M. Szabó: Canthares danubiens du III' siècle avant notre ère. EC19 (1982) 51-67.

= J. Malitz: Die Historien des Poseidonios. Zetemata 79. München 1983.

= A. Mócsy: Die Bevölkerung von Pannonien bis zu den Markomannenkriegen. Budapest 1959.

= A. Mócsy: Pannonia. In: PWRE Suppl. IX. Stuttgart 1962, 515-776.

= A. Mócsy: Pannonia and Upper Moesia. The provinces of the Roman Empire. London-Boston 1974

= V. ONDROUCH: Historische Voraussetzung für die Limesforschung in der Tschechoslowakei. In: A. Točik (éd.): Limes Romanus Konferenz Nitra. Bratislava 1959, 63-106.

= É. F. Petres: The problem of the celtic survival in Pannonia. Alba Regia 24 (1990) 7-15.

= K. Pieta-L. ZACHAR: Mladšia doba železné (laténska) (Le second Âge du Fer - La Tène). In: Najstaršie dejiny Bratislavy (La plus ancienne histoire de Bratislava). Bratislava 1993.

= P. C. RAMSL: Das latènezeitliche Gräberfeld von Mannersdorf. Wien 2011.

= A. Rustoiu-M. Egri: Danubian Kantharoi - almost three decades later. In: B. Berecki (éd.): Iron Age Communities in the Carpathian Basin. Cluj-Napoca 2010, 217-287.

= M. SzABó: Rapport entre l'Italie et la cuvette karpatique à la fin du Premier Âge du Fer et à l'époque de La Tène. In: D. Vitali (éd.): Celti ed Etruschi nell'Italia Centro-Settentrionale dal V sec. a.c. alla romanizzazione. Atti del colloquio internazionale, Bologna 12-14 aprile 1985. Bologna 1987, 35-46.

= M. Szabó: Les Celtes en Pannonie. Études d'histoire et archéologie 3. Paris 1988.

= M. Szabó: Les Celtes de l'Est. Le second Âge du Fer dans la cuvette des Carpates. Paris 1992.

= M. SzABó: Guerriers celtiques avant et après Delphes. In: J.-J. Charpy (éd.): L'Europe celtique du $\mathrm{V}^{\mathrm{e}}$ au III ${ }^{\mathrm{e}}$ siècle avant J.-C. Actes du deuxième symposium international d'Hautvillers, 8-10 octobre 1992. Sceaux 1995, 49-67.

= M. SzABÓ: L’expansion celte et l'armement décoré. MEFRA 108 (1996) 523-553.

= M. SZABÓ: Celticité danubienne. MEFRA 119 (2007) 5-15.

= M. SzABó: Lièvre celte de la puszta hongroise. In: Moments in Time. Papers presented to Pál Raczky on his $60^{\text {th }}$ birthday. Budapest 2013, 839-852.

= K. Tomaschitz: Die Wanderungen der Kelten in der antiken literarischen Überlieferung. MPK 47. Wien 2002.

= E. Tóтн: Die Entstehung der gemeinsamen Grenzen zwischen Pannonien und Noricum. AV 31 (1980) 80-88.

= L. ZACHAR-D. ReXA: Beitrag zur Problematik der spätlatènezeitlichen Siedlungshorizonte innerhalb des Bratislavaer Oppidums. ZbSNM 28 (1988) 27-72.

= P. ZsIDI (éd.): Kincsek a város alatt - Treasures Under the City. Survey of the archaeological heritage of Budapest, 1989-2004. Budapest 2005. 